\title{
A Method of Evaluating Stream Function for Ocean Currents.
}

\author{
Mituyo OKADA
}

(The Imperial Fisheries Institute, Tôkyô)

The stream lines of steady surface current can most conveniently be represented as the loci of constant values of the stream function $\psi$, provided that the water flows practically horizontally or in two dimensions. In the case of estimating ocean currents based on the observations of salinity and soluble silicate content, as was previously studied by the present writer ${ }^{1}$, the stream function can easily be expressed in terms of the observed quantities, and the numerical processes for the evaluation can be considerablly facilitated by the aid of iso-line charts of both the quantities.

On nearly the same assumptions as those made in the case of the preceding graphical method of determining ocean current ${ }^{2}$, the equations of continuity of water, of salinity $S$ and of silicate $P$ in the layer ranging from the water surface $z=0$ to a certain depth $z=h$, are

$$
\operatorname{div} \vec{v}=0^{3)}, \quad \vec{v} \operatorname{grad} \bar{S}=\frac{\nu}{h}\left(\frac{\partial S}{\partial z}\right)_{z=h} \text { and } \bar{v} \operatorname{grad} \bar{\Gamma}=\frac{\nu}{h}\left(\frac{\partial P}{\partial z}\right)_{z+h},
$$

where $\mathfrak{v}$ is the velocity of the current considered to be horizontal ${ }^{3)}$, the barred quantities are the averages taken from $z=0$ to $z=h$ and $\nu$ the coefficient of eddy diffusivity, the rertical gradients of $S$ and $P$ at $z=0$ being put to be 0 because of the assumption that there are neither precipitation nor evaporation effective to dilute or concentrate the sea water ${ }^{4)}$. Denoting the unit vector in z-direction by

$$
\bar{v}=[\mathfrak{g r a d} \psi]
$$

and

$$
[\mathfrak{f} \operatorname{grad} \psi] \operatorname{grad} \bar{S}=-[\mathfrak{f} \operatorname{grad} \bar{S}] \operatorname{grad} \psi=-\frac{\partial S}{\partial n} \frac{\partial \psi}{\partial s},
$$

where $d n$ and $d s$ denote the line elements in the direction of $\operatorname{grad} \bar{S}$ and $[\hat{\mathfrak{t}}$ $\operatorname{grad} \bar{S}]$, i. e. in the direction of the normal and the tangent to the iso-haline curve.

1) OKADs, M.; Bull. Jap. Soc. Sci. Fish., 3 (3), 1934, 121 124.

2) — ; Bull. Jap. Soc. Sci. Fish., $3(5), 1935$, 231 234.

3) At time, $\partial w / \partial z$ in this equation can not be dropped and then the present method fails. See Ekmax, V. W. : Meeresströmungen. Handb. der physik. u. tochn. Mechanik, herausg. von AUERBACH, F, und W. Hort, 5 (1), 1927, S. 178 179.

4) When the current in an intermediate layer is dealt with, the terms of $(\partial S / \partial z)$ and $(\partial P / \partial z)$ at $z=0$ must of course be retained. See Trorade, H.: Untersuchung von Strömungen mittels der Kontinuitätsgleiehung. Ann. d. Hydrogr. u. s. w., 36 (8), Aug. 1935, 316 317. 
From (1), (2) and (3), we get

$$
\frac{\partial \psi}{\partial s}=-\frac{\nu}{h}\left(\frac{\partial S}{\partial z}\right)_{z=h} /\left(\frac{\partial \bar{S}}{\partial n}\right)
$$

with which the difference in $\psi$ along an iso-haline curve can be evaluated by the numerical integration from the observed salinity, if $\nu$ be known in any other way.

A similar relation can be obtained from the third equation of (1) for silicate iso-lines. The stream function can, thus, be determined over the region, which is covered by the net of iso-line systems of the both kinds.

On applying the method to the observational data, first fix the suitable thickness of the surface layer $h$, evaluat the mean values, $\bar{S}$ and $\bar{P}$, and plot them on a chart. On another chart draw the map showing the distributions of $\partial S / \partial z$ and $\partial P / \partial z$ at the level of $h$. The latter chart is better drawn on an oiled paper, so that we can place it on the first chart and read off the values at any desired point on the first. The same units for $S$ and $P$ as used in the first chart and a common unit of $z$ must be employed to evaluate the vertical gradients.

Take, if not all, the points of intersection between iso-lines of $\bar{S}$ and $\bar{P}$ drawn on the first chart, every next two on an iso-line in pair. Let the length of the segment of isoline between the paired points, $\Delta s$, and the mean breadth between two adjacent iso-lines along the segment, $b$, be measured with each pair. (See Fig. 1). The sense in which $\Delta s$ is measured, say from $a$ to $b$ in Fig. 1, shall be so fixed that the next iso-line having larger value lies to the left of the segment. Then, using the mean value of the vertical gradient, say $\partial S / \partial z$, taken along the segment, calculate the increment of the stream function from $a$ to $b$ by the equation:

$$
\Delta \psi=-\frac{\nu}{h} b\left(\frac{\partial S}{\partial z}\right)_{z=h} \Delta s
$$

which can be derived, as an approximation, from (4). Choosing somo point as the origin, evaluate $\psi$ by summing up $\Delta \psi$ 's from segment to segment. In this summation, however, some smoothing on the prepared values is necessary. The method of least square can be applied, if we express the stream function as a polynomial in $\bar{S}$ and $\bar{P}$, of which the partial differential coefficients are known from the material. But, this is too tedious because the polynomial must at least be of higher order than the third. The simplest way was followed instead in the examples to be mentioned below. Let abed in Fig. 1 be a mesh of the iso-line net, and $\psi$ increases from a to d. If $\psi_{a}$, or $\psi$ at a, has already been determined, next the sum of $\Delta \psi$ 's on $a b$ and bd and that on ac and ed are averaged and added to $\psi_{a}$. The resulting sum is taken as $\psi_{a}$. 
Similarly $\psi_{\prime \prime}^{\prime}, \psi_{\prime \prime}^{\prime \prime}, \ldots$ arc determined. Next $\psi$ at the points arranged on the adjacent diagonal line, $a s b, b^{\prime}, b^{\prime \prime}, \ldots$ or $c, c^{\prime}, c^{\prime \prime}, \ldots$, are determined so as to keep the similar condition for each mesh, and, besides, to disturb as least as possible the ratios of $\Delta \psi$ on two legs such as ab and $b d$, or as ac and cd.

As will be seen in the following example, there are cases, in which the same pair of the iso-lines of $\bar{S}$ and $\bar{P}$ osculate or more commonly cut with each other at both ends of the segment,

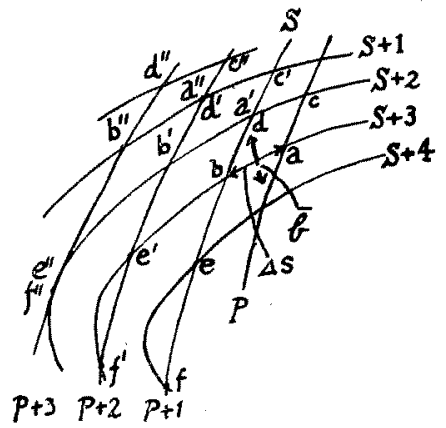

Fig. 1. as $e$ and $f$ in Fig. 1. If, in such a case, $\psi$ increases, along an iso-line in an opposite sense to that along another, the present method fails essentially and we must consider that our assumptions are unsound. Such points lie generally on a line, along which the inferred stream lines become discontinuous. But, as for the existence of such lines of discontinuity in reality,

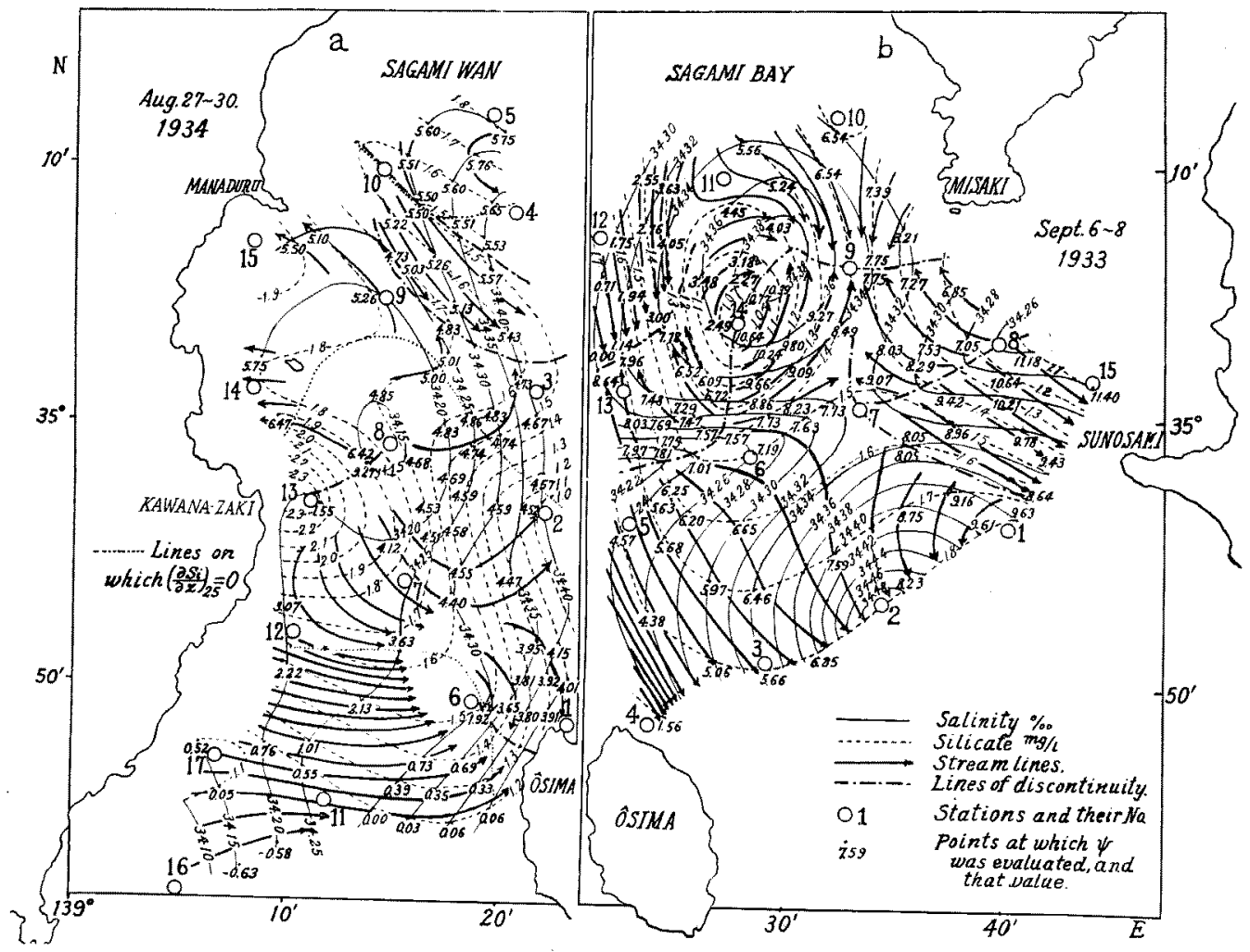

Fig. 
nothing but more detailed observations and more advanced investigations can give a decisive conclusion.

The equation (2) shows that $\psi$ is greater to the left of the current than to the right. As we have neglected the mixing in the horizontal directions, current is directed to the region of greater $\bar{S}$ or $\bar{P}$, where $\partial S / \partial z$ or $\partial P / \partial z$ is positive and vice versa. This is clearly seen from (5).

The present method was applied to the data of observations got on the hydrographical excursions which were made by the students on board the "Seityomaru" of the Imperial Fisheries Institute, in the eastern part of Sagami Bay in 1933, ${ }^{1}$ ' and in the western part in August 1934 (Table 1).

Thickness, $h=25 \mathrm{~m}$., and $\partial S / \partial z$ and $\partial P / \partial z$ were similarly determined as in the case of preceding graphical

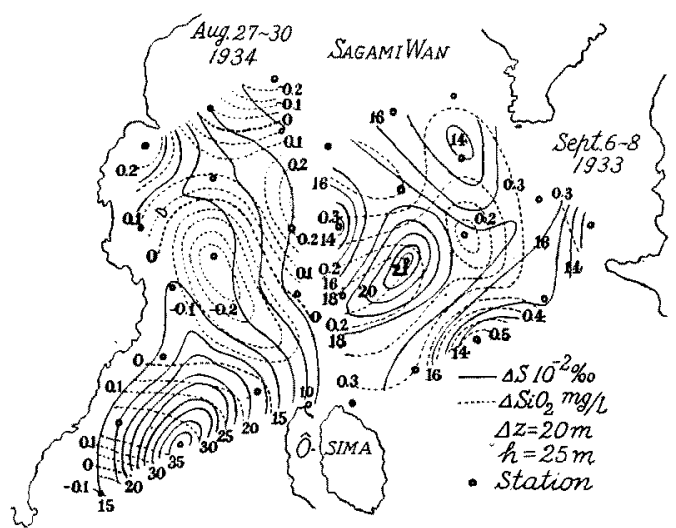

Fig. 3. Two fifths of the differences of $\mathrm{S}$ or $\mathrm{SiO}_{2}$ at $50 \mathrm{~m}$ from that at the surface.

method. Horizontal leugths were measured in $\mathrm{km}$, while the vertical in $20 \mathrm{~cm}$. The stream function was calculated excepting the constant factor $v / h$. Hence, to estimate the speed of the current in $\mathrm{m} / \mathrm{s}$, the difference in $\psi$ for $1 \mathrm{~km}$ must be multiplied by $\nu \times 10^{3} /\left(4 \times 1.25 \times 10^{4}\right)=\nu / 50$, where $\nu$ is expressed in $\mathrm{cm}^{2} / \mathrm{s}$.

The stream lines inferred in the eastern part of the Bay, (Fig. 2, b), stand of course in good coincidence with those current vectors obtained graphically in the preceding report. The singularity at the diverging centre in the western part (Fig. 2, a) between Ôsima and Manaduru is seen also in the distribution of temperature etc. at various levels and even in the colour and transparency (Table 1). The wind, not very strong as it was, blew in different directions from day to day (Table 1), suggesting that the current was never in a stationary state. It is still worth noticing that in the central part of the Bay, there are no essential discrepancies in the directions of current between the results obtained in different years.

In conclusion the writer's best thanks are due to Mr. M. Sinoda and all the studunts and the crew of the "Seityomaru" for the help of the obserrations.

1) Semi-annual Rep. Ocean. Inv. Fisher. Exper. Stat., (53), 1984, p. 52 and p. 288. 
Table 1. Hydrographical conditions in Sagami Bay. Aug. 27 to 30, 1934.

\begin{tabular}{|c|c|c|c|c|c|c|c|c|c|c|c|c|c|}
\hline \multicolumn{2}{|c|}{ Stations } & 1 & 3 & 3 & 4 & 5 & 7 & 8 & 10 & 12 & 13 & 14 & 15 \\
\hline \multicolumn{2}{|c|}{ N-lat. } & $34^{\circ}$ & "I & $35^{\circ}$ & $" 1$ & " & $34^{\circ}$ & " & $35^{\circ}$ & $34^{\circ}$ & " & $35^{\circ}$ & " \\
\hline \multirow{3}{*}{\multicolumn{2}{|c|}{ E-long. }} & $48 \cdot 5^{\prime}$ & $56 \cdot 4^{\prime}$ & $1 \cdot 2^{\prime}$ & $8 \cdot 1^{\prime}$ & $11 \cdot 9^{\prime}$ & $53 \cdot 9^{\prime}$ & $59 \cdot 2^{\prime}$ & $9 \cdot 9^{\prime}$ & $52 \cdot 1^{\prime}$ & $57.0^{\prime}$ & $2 \cdot 8^{\prime}$ & $7 \cdot 3^{\prime}$ \\
\hline & & $139^{\circ}$ & " & " & " & $"$ & " & " & " & " & " & " & $"$ \\
\hline & & $\mathbf{2 3 \cdot 3 ^ { \prime }}$ & $22 \cdot 4^{\prime}$ & $21 \cdot 6^{\prime}$ & $20 \cdot 8^{\prime}$ & $19 \cdot 8^{\prime}$ & $15 \cdot 4^{\prime}$ & $14 \cdot 8^{\prime}$ & $14 \cdot 5^{\prime}$ & $10 \cdot 2^{\prime}$ & $11 \cdot 1^{\prime}$ & $8 \cdot 3^{\prime}$ & $8 \cdot 3^{\prime}$ \\
\hline \multirow{3}{*}{\multicolumn{2}{|c|}{$\begin{array}{c}\text { Date } \\
\text { Time h-m }\end{array}$}} & 27 & $"$ & " & " & $"$ & 38 & " & 27 & 29 & " & 28 & 27 \\
\hline & & $6-25$ & $8-26$ & $9-49$ & $11-09$ & $12-16$ & $9-25$ & $8-12$ & $13--25$ & $10-47$ & $9-34$ & $6-48$ & $15-52$ \\
\hline & & $7-19$ & $9-11$ & $10-24$ & $11-37$ & $12-48$ & $9-55$ & $8-40$ & $14-00$ & $11-161$ & 10-01 & $7-15$ & $16-28$ \\
\hline \multicolumn{2}{|c|}{ Temp. 0m } & $24 \cdot 14$ & $24 \cdot 27$ & $25 \cdot 73$ & $25 \cdot 30$ & 25.28 & $26 \cdot 05$ & $24 \cdot 25$ & $25 \cdot 85$ & 24.80 & $26 \cdot 15$ & $25 \cdot 08$ & $25 \cdot 66$ \\
\hline \multirow[t]{4}{*}{${ }^{\circ} \mathrm{C}$} & 25 & $22 \cdot 30$ & $22 \cdot 46$ & $20 \cdot 20$ & $21 \cdot 49$ & $21 \cdot 43$ & 22.73 & $24 \cdot 14$ & $23 \cdot 04$ & $21 \cdot 70$ & $23 \cdot 15$ & $22-87$ & 21.63 \\
\hline & 50 & $17 \cdot 00$ & $18 \cdot 31$ & $18 \cdot 34$ & $16 \cdot 83$ & $18 \cdot 54$ & $16 \cdot 77$ & $24 \cdot 05$ & $17 \cdot 70$ & $19 \cdot 43$ & $18 \cdot 27$ & $16 \cdot 77$ & $17 \cdot 22$ \\
\hline & 100 & $14 \cdot 48$ & $14 \cdot 21$ & $13 \cdot 24$ & $13 \cdot 77$ & $14 \cdot 69$ & $14 \cdot 50$ & 14.23 & $13 \cdot 71$ & 14.59 & $15 \cdot 35$ & $15 \cdot 7$ & $14 \cdot 76$ \\
\hline & 300 & 10.83 & $10 \cdot 96$ & $10 \cdot 31$ & $10 \cdot 75$ & $11 \cdot 26$ & $11 \cdot 29$ & $12 \cdot 10$ & $11 \cdot 26$ & 12.38 & 11.26 & - & 11.30 \\
\hline $\mathrm{S}$ & $0 \mathrm{~m}$ & 34.25 & $34 \cdot 43$ & $34 \cdot 33$ & 34.23 & $34 \cdot 16$ & $34 \cdot 16$ & $33 \cdot 96$ & 34.23 & $34 \cdot 18$ & $34 \cdot 16$ & $34 \cdot 18$ & 33.98 \\
\hline \multirow[t]{4}{*}{8} & 25 & 34.78 & $34 \cdot 37$ & $34 \cdot 51$ & 34.63 & $34 \cdot 37$ & $34 \cdot 33$ & $34 \cdot 18$ & $34 \cdot 31$ & 34.24 & 34.23 & $34 \cdot 19$ & 34.51 \\
\hline & 50 & $34 \cdot 41$ & 34.58 & 34.52 & $34 \cdot 36$ & 34.23 & $34 \cdot 54$ & $34 \cdot 32$ & 34.43 & 34.56 & 34.54 & 34.52 & 34.55 \\
\hline & 100 & $34 \cdot 55$ & $34 \cdot 63$ & 34.52 & 34.52 & $34 \cdot 61$ & $34 \cdot 67$ & $34 \cdot 87$ & 34.58 & 34.57 & $34 \cdot 47$ & 34.60 & 34.59 \\
\hline & 200 & 34.42 & $34 \cdot 42$ & $34-48$ & 34.54 & 34.33 & - & 34.22 & 34.02 & 34.47 & $34-38$ & - & 34.52 \\
\hline \multirow{5}{*}{$\begin{array}{l}\mathrm{SiO}_{2} \\
\mathrm{mg} / 1\end{array}$} & $0 \mathrm{~m}$ & 1.25 & $1 \cdot 48$ & 1.07 & 1.52 & 1.85 & $3 \cdot 13$ & $3 \cdot 48$ & 1.88 & 1.48 & $2 \cdot 56$ & 1.86 & 1.88 \\
\hline & 25 & 1.00 & 0.42 & $2 \cdot 10$ & 1.57 & 1.84 & 1.47 & 2.00 & 1.54 & 1.74 & $2 \cdot 24$ & 1.74 & 2.03 \\
\hline & 50 & 1.06 & 1.48 & 1.66 & 1.55 & $1 \cdot 18$ & 1.91 & $1 \cdot 76$ & 1.54 & $1 \cdot 34$ & 2.37 & 2.07 & $2 \cdot 46$ \\
\hline & 100 & $1 \cdot 6 *$ & 1.32 & $2 \cdot 64$ & $2 \cdot 41$ & 1.98 & $1 \cdot 96$ & $2 \cdot 80$ & 346 & 1.64 & 2.52 & $2 \cdot 53$ & $2 \cdot 20$ \\
\hline & 200 & 1.93 & 1.88 & 1.82 & 1.60 & $1 \cdot 41$ & 2.09 & $2 \cdot 01$ & $3 \cdot 14$ & $3 \cdot 81$ & $2 \cdot 82$ & - & $2 \cdot 31$ \\
\hline \multirow{2}{*}{\multicolumn{2}{|c|}{$\begin{array}{c}\text { Colour } \\
\text { Transp. m }\end{array}$}} & 3 & $3-4$ & 3 & 4 & $4-5$ & $3-4$ & $3-4$ & 4 & 4 & 2 & 4 & $3-4$ \\
\hline & & 95 & 20 & 25 & 21 & 17 & 32 & 23 & 21. & 17 & 21 & 15 & 14 \\
\hline \multirow{4}{*}{\multicolumn{2}{|c|}{$\begin{array}{l}\text { Air-temp. } \\
\text { Wind } \\
\text { "-vel. m/s } \\
\text { Weather }\end{array}$}} & $25 \cdot 8$ & $26 \cdot 5$ & $26 \cdot 8$ & 27.6 & 27.5 & $27 \cdot 4$ & 25.8 & 28.4 & $28 \cdot 4$ & $28 \cdot 4$ & $25 \cdot 5$ & 26.8 \\
\hline & & ESE & NNE & $\mathrm{NE}$ & NNE & ENE & $\mathrm{N}$ & $\mathbf{N}$ & $\mathbf{E}$ & $\mathrm{S}$ & $-\ldots$ & $\mathrm{N}$ & $\mathrm{S}$ \\
\hline & & $2 \cdot 5$ & $1 \cdot 1$ & 4.7 & $2 \cdot 6$ & $3 \cdot 8$ & 8.7 & 8.7 & 2.5 & $1 \cdot 2$ & 0 & $5 \cdot 7$ & $5 \cdot 8$ \\
\hline & & $\mathrm{b}$ & $\mathrm{bc}$ & $\mathrm{b}$ & $\mathrm{b}$ & c & $\mathrm{bc}$ & bc & $b$ & be & be & $\mathrm{c}$ & c \\
\hline \multicolumn{2}{|c|}{ Stat. } & 6 & 9 & 11 & 16 & 17 & \multicolumn{2}{|c|}{ Stat. } & 6 & 9 & 11 & 16 & 17 \\
\hline \multirow{3}{*}{\multicolumn{2}{|c|}{$\begin{array}{l}\text { N-lat. } \\
\text { E-long. }\end{array}$}} & $34^{\circ}$ & $35^{\circ}$ & $34^{\circ}$ & 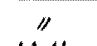 & $\because$ & \multirow{2}{*}{\multicolumn{2}{|c|}{$\begin{array}{c}\text { Date } \\
\text { Time } h-m\end{array}$}} & * 0 & & .00 & 29 & 29 \\
\hline & & $\begin{array}{l}49 \cdot 6^{\prime} \\
139^{\circ} \\
78 \cdot 8^{\prime}\end{array}$ & $4 \cdot 9$ & $\begin{array}{c}45 \cdot 5^{\prime} \\
\prime \prime \\
11.8^{\prime}\end{array}$ & $\begin{array}{c}4.4 \\
/ 7\end{array}$ & $\begin{array}{c}47 \cdot 3 \\
11\end{array}$ & & & $\begin{array}{l}11-31 \\
11-59\end{array}$ & $\begin{array}{l}14-40 \\
15-12\end{array}$ & $\begin{array}{l}10-25 \\
10-57\end{array}$ & $\begin{array}{l}14-08 \\
14-41\end{array}$ & $\begin{array}{ll}3 & 12-37 \\
13-05 & 13-5\end{array}$ \\
\hline & & & & & & & \multirow{4}{*}{$\begin{array}{l}\mathrm{S} \\
0 \\
0\end{array}$} & $0 \mathrm{~m}$ & $34 \cdot 11$ & 34.23 & 3407 & $34 \cdot 17$ & $34 \cdot 11$ \\
\hline \multirow{3}{*}{\multicolumn{2}{|c|}{$\begin{array}{r}\text { Temp. } \\
{ }^{c} \mathrm{C} \\
\\
25 \\
50 \\
75 \\
150\end{array}$}} & 27.05 & $25 \cdot 85$ & $25 \cdot 15$ & & 27.65 & & 35 & 3437 & $34 \cdot 16$ & $34 \cdot 49$ & $33 \cdot 87$ & $34 \cdot 30$ \\
\hline & & $\begin{array}{l}22.51 \\
19 \cdot 3\end{array}$ & $\begin{array}{l}33 \cdot 96 \\
19 \cdot 24\end{array}$ & $\begin{array}{l}21.66 \\
18.98\end{array}$ & $\begin{array}{l}22.84 \\
18.87\end{array}$ & $\begin{array}{l}23.38 \\
18 \cdot 40\end{array}$ & & 5 & $\begin{array}{l}34 \cdot 64 \\
34 \cdot 60\end{array}$ & $\begin{array}{l}34.51 \\
34.58\end{array}$ & 35.00 & & \\
\hline & & $\begin{array}{l}19 \cdot 4 \\
15.0\end{array}$ & 1440 & $16 \cdot 09$ & 16.63 & $17 \cdot 60$ & & $\begin{array}{r}10 \\
150\end{array}$ & 34.56 & $34 \cdot 65$ & $35 \cdot 17$ & 34.53 & 34.51 \\
\hline \multirow{2}{*}{\multicolumn{2}{|c|}{$\begin{array}{c}\text { Colour } \\
\text { Transp. m }\end{array}$}} & & & & & & $\mathrm{SiC}$ & $0 \mathrm{~m}$ & 1.63 & $1 \cdot 88$ & 1.28 & 1.24 & 1.08 \\
\hline & & 13 & $\begin{array}{r}4 \\
17\end{array}$ & $\begin{array}{r}3 \\
31\end{array}$ & 18 & $\begin{array}{r}3 \\
22\end{array}$ & & 50 & 1.70 & $\begin{array}{l}1.68 \\
2.13\end{array}$ & $\begin{array}{l}1.06 \\
1.74\end{array}$ & $\begin{array}{l}1.09 \\
0.99\end{array}$ & $\begin{array}{l}1.06 \\
1.76\end{array}$ \\
\hline \multirow{2}{*}{\multicolumn{2}{|c|}{$\begin{array}{l}\text { Air-temp. } \\
\text { Wind } \\
\text { "/-vel. } \mathrm{m} / \mathrm{s}\end{array}$}} & $\begin{array}{l}27 \cdot 6 \\
\text { SW }\end{array}$ & $\begin{array}{r}278 \\
\text { SSE }\end{array}$ & $\begin{array}{l}265 \\
\text { SSW }\end{array}$ & $\underset{\mathrm{S}}{28 \cdot 2}$ & $28 \cdot 1$ & & $\begin{array}{r}75 \\
150 \\
\end{array}$ & $\begin{array}{l}1 \cdot 90 \\
2 \cdot 11\end{array}$ & $\begin{array}{l}3.00 \\
2.58\end{array}$ & $\begin{array}{l}1 \cdot 48 \\
1.86\end{array}$ & $\begin{array}{l}1.29 \\
2 \cdot 14\end{array}$ & $\begin{array}{l}1.80 \\
1.21\end{array}$ \\
\hline & & $11 \cdot 2$ & 60 & $7 \cdot 7$ & 50 & 47 & \multicolumn{2}{|c|}{ Weather } & $\mathrm{b}$ & $\mathrm{b}$ & $\mathrm{bc}$ & $b c$ & be \\
\hline
\end{tabular}

